\title{
HUBUNGAN ANTARA PENYESUAIAN DIRI DAN RASA EMPATI DENGAN INTERAKSI SOSIAL PADA SISWA KELAS XI IPS DI SMA NEGERI 1 ARGAMAKMUR
}

\author{
Sella Nopela, Rita Sinthia \\ Prodi Bimbingan dan Konseling Fakultas Keguruan dan Ilmu Pendidikan \\ Universitas Bengkulu \\ sellanopel@gmail.com, hadiwin@unib.ac.id, ritasinthia@unib.ac.id
}

\begin{abstract}
ABSTRAK
Penelitian ini bertujuan untuk mengetahui hubungan antara penyesuaian diri dan rasa empati dengan interaksi sosial pada siswa kelas XI IPS di SMA Negeri1 Argamakmur. Penelitian ini adalah penelitian korelasi dengan instrument angket. Teknik pengumpulan data melalui angket hubungan antara penyesuaian diri dan rasa empati dengan interaksi sosial teknik korelasi product moment dan korelasi ganda. Hasil yang di peroleh dalam penelitian adalah hubungan yang signifikan antara penyesuaian diri dengan interaksi sosial dengan nilai $\mathrm{rx}_{1} \mathrm{y} 0,512$. Adanya hubungan yang signifikan antara penyesuaian diri dengan interaksi sosial $\mathrm{f}$ dengan nilai $\mathrm{rx}_{2} \mathrm{y}$ 0,802 dan adanya hubungan yang signifikan antara penyesuaian diri dan rasa empati dengan interaksi dengan nilai $\mathrm{rx}_{1} \mathrm{x}_{2} \mathrm{y}$ 0.684. Dari hasil penelitian ini dapat disimpulkan bahwa adanya hubungan korelasi yang signifikan antara penyesuaian diri dan rasa empati dengan interaksi pada siswa kelas XI IPS di SMA Negeri 1 Argamakmur dengan tingkat hubungan kuat.
\end{abstract}

Kata kunci : penyesuaian diri, rasa empati, interaksi sosial

\section{CORRELATION OF ADJUSTMENT AND EMPAHTY TO SOCIAL INTERACTIONS OF TWO GRADE STUDENTS MAJORINGIN SOCIAL PROGRAMAT SMANEGERI 1 ARGAMAKMUR}

\begin{abstract}
This study aims to study the relationship between self and empathy with social interaction in social studies class XI students at SMA Negeri 1 Argamakmur. This study is a correlation study with a questionnaire instrument. Data collection techniques through a questionnaire the relationship between adjustment and empathy with social interaction product moment correlation techniques and multiple correlation. The results obtained in the study are significant relationships between adjustment and social interaction with a value of rx1y 0.512 . There is a significant relationship between adjustment and social interaction $f$ with a value of rx $2 y 0.802$ and a significant relationship between adjustment and a sense of empathy with interactions with a value of rx1x2y 0.684 . From the results of this study it can be concluded that there is a significant correlation between the adjustment and empathy with the interaction in students of class XI IPS in SMA Negeri 1 Argamakmur with a strong relationship level
\end{abstract}

Keywords : adjustment, empathy, social interactions 
Nopela, Sinthia

\section{Pendahuluan}

Manusia merupakan makhluk sosial yang memiliki kaitan erat dengan manuisa lainnya. Dalam kehidupan sehari-hari manusia memerlukan interaksi dengan manusia lain seperti berkomunikasi agar dapat bergaul dan menjalin kekerabatan antar sesama manusia. Dalam era millennial saat ini, kebutuhan berinteraksi antar sesama manusia semakin besar baik dalam kelompok kecil ataupun kelompok besar. Interaksi sosial juga menjadi pondasi dalam menjalin hubungan antar sesama manusia sebagai makhluk sosial. Agar interaksi sosial terjalin dengan baik maka untuk menerapkannya dalam kehidupan sehari-hari membutuhkan nilai sosial dan norma yang berlaku agar interaksi sosial dapat tercipta dengan baik. Menurut Ardi (2016:22) hubungan antar individu, antar kelompok, atau antara individu dengan kelompok adalah suatu hal yang dinamis sebagai ciri-ciri dari suatu interaksi sosial. Menurut Anwar (2016: 8) interaksi sosial dapat dikatakan sebagai suatu proses penyesuaian diri dari individu satu ke individu lain, dimana kedua individu ini dapat saling terpengaruhi oleh adanya interaksi tersebut.

Adanya norma dan nilai sosial yang berkembang dimasyarakat menjadikan hal itu sebagai dasar setiap manusia dalam bertingkah laku yang dilandasi dengan moral agar sesuai dengan aturan yang berlaku dimasyarakat serta tidak bertentangan dengan prinsip, etis, maupun kaidah. Norma dan nilai sosial ini menjadi landasan atau alasan pentingnya sebuah penyesuaian diri bagi manusia terutama bagi diri siswa. Menurut Latifah (2015: 26) menyatakan bahwa penyesuaian diri dapat diartikan sebagai usaha manusia untuk mencapai harmoni pada diri sendiri dan pada lingkungan, sehingga rasa permusuhan, dengki, iri hati, prasangka, depresi, kemarahan dan emosi negatif yang lain sebagai respon pribadi yang tidak sesuai dan kurang efisien bisa dikikis habis.

Penyesuaian diri yang dilakukan manusia untuk menyeimbangkan diri dengan lingkungan sekitarnya juga menjadikan manusia sebagai individu yang memiliki kepekaan sosial yaitu rasa empati. Rasa empati terbentuk karena penyesuaian diri yang baik terhadap suatu individu, sehingga rasa empati juga menjadi suatu hal yang penting untuk meningkatkan sebuah interaksi sosial. Menurut Fitriyah (2016: 22) berpendapat bahwa empati merupakan keadaan afektif yang seolah - olah dialami sendiri yang berasal dari keadaan atau kondisi emosi orang lain yang mirip dengan keadaan atau kondisi orang tersebut. Empati dianggap sebagai faktor yang penting dalam 
mengembangkan perilaku yang positif terhadap orang lain. Empati akan membuat seseorang menjadi bijaksana dalam perasaan.

Fenomena yang terjadi banyak menyita perhatian para pendidik. Salah satunya adalah kurangnya interaksi di sekolah kerana rendahnya interaksi sosial. Penelitian mengenai interaksi sosial beberapa tahun terakhir menunjukkan rendahnya interaksi sosial di sekolah yang tidak sedikit meskipun tidak bisa dikatakan banyak. Hasil studi pendahuluan ditemukan beberapa kasus interaksi sosial di kalangan siswa. Hasil wawancara dengan salah satu guru bimbingan konseling di sekolah SMA Negeri 1 Argamakmur mendapatkan hasil yaitu pada umumnya masih terdapat peserta didik yang terlihat sombong sehingga dijauhi dengan teman-temanya kerena sering mengejek temannya yang tidak mampu dalam segi ekonomi, ada siswa yang sering menjahili temannya saat mengerjakan tugas, terdapat peserta didik yang sering meminta uang jajan teman - temannya saat istirahat berlangsung, ada siswa yang sering mengamuk jika diejek oleh temannya, terdapat siswa yang sering melamaun disaat pelajaran berlangsung dikarenakan kurangnnya konsentrasi pada peserta didik tersebut. Siswa merasa malas untuk bertanya jika kurang jelas dengan materi yang sedang dijelaskan karena sedang asik mengobrol dengan teman sebangkunya dan merasa takut jika nanti dikira bodoh oleh teman-temannya yang lain, siswa kurang berperan aktif dalam kelompok dan kurangnya kepercayaan diri, selain itu siswa belum bisa mengakui kesalahannya sendiri atau belum mempunyai kesadaran diri yang baik.

Pentingnya penelitian ini dilakukan dalam layanan bimbingan dan konseling agar dapat memberikan pemahaman tentang penyesuaian diri dan rasa empati yang sangat penting serta interaksi sosial sebagai salah satu faktor yang mempengaruhinya. Melalui kenyataan di atas penulis tergugah untuk melakukan penelitian dengan tujuan untuk mengetahui hubungan antara penyesuaian diri dan rasa empati dengan interaksi sosial.

\section{Metode Penelitian}

Metode yang digunakan dalam penelitian ini adalah metode deskriptif kuantitatif, dengan teknik korelasi. Teknik korelasi adalah suatu penelitian yang dilakukan dengan mengumpulkan sejumlah data untuk mengetahui serta menentukan ada tidaknya hubungan antara dua variabel atau lebih guna mengukur seberapa besarnya tingkat hubungan kedua variabel yang diukur tersebut (Darmadi, 2014: 206). Populasi dalam penelitian ini adalah siswa kelas XI IPS di SMA Negeri 1 Argamakmur. Jumlah kelas XI IPS sebanyak 4 kelas dan jumlah seluruh populasi pada 
penelitian ini adalah 126 siswa. Teknik pengambilan sampel yang digunakan pada penelitian ini yaitu Simple Random Sampling merupakan sampel yang digunakan secara acak. Sampel pada penelitian ini terbagi menjadi dua, yaitu: sampel uji coba dan sampel penelitian. Sampel uji coba berjumlah 30 orang dan sampel penelitian berjumlah 96 orang.

Teknik pengumpulan data dilakukan dengan menggunakan kuesioner atau angket penyesuaian diri, rasa empati dan interaksi sosial dengan model Skala Likert. Teknik analisis data yang digunakan adalah Korelasi Ganda, yang dilakukan dengan bantuan aplikasi komputer yaitu program Statistical Packages for Sosial Science (SPSS) dengan bantuan inilah nantinya diperoleh hubungan antara kedua variabel dan taraf signifikannya dalam menentukan kekuatan dan arah hubungannya. Analisis hasil uji coba pada penelitian ini menggunakan bantuan software SPSS versi 16 for windows. Langkah awal adalah menguji validitas butir kuesioner dengan melakukan uji coba kuesioner ke sejumlah responden sampel uji coba. Berdasarkan hasil uji validitas kuesioner diperoleh hasil bahwa kuesioner penyesuian diri yang disebarkan ke 30 responden yang terdiri dari 40 item pernyataan didapatkan 8 item yang dinyatakan gugur dan 32 item yang dinyatakan valid. Skor item valid terendah pada instrument penyesuaian diri yaitu 0,371 dan skor tertinggi 0,750 . Berdasarkan hasil uji validitas kuesioner diperoleh hasil bahwa kuesioner rasa empati yang disebarkan ke 30 responden yang terdiri dari 40 item pernyataan didapatkan 5 item yang dinyatakan gugur dan 35 item yang dinyatakan valid. Skor item valid terendah pada instrument penyesuaian rasa empati yaitu 0,389 dan skor tertinggi 0,672. Berdasarkan hasil uji validitas kuesioner diperoleh hasil bahwa kuesioner interaksi sosial yang disebarkan ke 30 responden yang terdiri dari 40 item pernyataan didapatkan 8 item yang dinyatakan gugur dan 32 item yang dinyatakan valid. Skor item valid terendah pada instrument interaksi sosial yaitu 0,353 dan skor tertinggi 0,729 .

Uji reliabilitas penyeusian diri, rasa empati dan interaksi sosial ini menggunakan reliability analysis scale (Cronbach's alpha) dengan bantuan program komputer software Statistical Packages for Social Science (SPSS) versi 16 for windows. Peneliti menggunakan reliability analysis scale (Cronbach's alpha) karena rumus Cronbach's alpha lebih cocok digunakan pada kuesioner dengan skor jawaban dalam bentuk gradasi, seperti skala Likert yang menggunakan skor 1,2,3,4. Hasil uji reliabilitas menunjukkan hasil bahwa Koefisien reliabilitas pada 
instrument penyesuaian diri yaitu 0,902, koefisien reliabilitas pada instrument rasa empati yaitu 0,928 dan koefisien reliabilitas pada instrument interaksi sosial yaitu 0,916.

\section{Hasil dan Pembahasan}

Deskripsi data yang disajikan pada bagian ini adalah deskripsi tentang masing-masing variabel, yang diteliti antara lain variabel terikat yaitu interaksi sosial (Y), variabel bebas penyesuaian diri (X1), variabel bebas rasa empati (X2). Deskripsi tentang interaksi sosial, penyesuaian diri dan rasa empati diperoleh dari hasil penyebaran kuesioner ke sejumlah responden yang menjadi sampel penelitian.

Berdasarkan skor yang diperoleh, didapatkan gambaran umum skor penyesuaian diri yang dihitung berdasarkan skor ideal. Diperoleh gambaran tentang penyesuaian diri dengan skor minimum sebesar 32 , skor maximum sebesar 128 , rata-rata sebesar 80 , dan standar deviasinya sebesar 16. Selanjutnya skor-skor di kategorisasi. Subjek digolongkan ke dalam tiga kategori penyesuaian diri, yaitu tinggi, sedang, dan rendah.. Secara ringkas perhitungan kategorisasi dapat dilihat pada Tabel 1.

Tabel 1

Tabel Distribusi Frekuensi Data Penyesuaian Diri

\begin{tabular}{cccc}
\hline Kategori & Rentang Skor & Frekuensi & $\begin{array}{c}\text { Persentase } \\
(\boldsymbol{\%})\end{array}$ \\
\hline Rendah & $32-63$ & 4 & $4,16 \%$ \\
\hline Sedang & $64-95$ & 59 & $61,45 \%$ \\
\hline Tinggi & $96-128$ & 33 & $34,37 \%$ \\
\hline & Total & 96 & $100 \%$ \\
\hline
\end{tabular}

Berdasarkan Tabel di atas dapat dilihat bahwa subjek yang memiliki penyesuaian diri rendah sebanyak 4 orang $(4,16 \%)$, subjek yang memiliki penyesuaian diri sedang sebanyak 58 orang $(60,41 \%)$, dan subjek yang memiliki penyesuaian diri tinggi sebanyak 33 orang $(34,37 \%)$.

Berdasarkan skor yang diperoleh, didapatkan gambaran umum skor rasa empati yang dihitung berdasarkan skor ideal. Diperoleh gambaran tentang rasa empati dengan skor minimum sebesar 35, skor maximum sebesar 140 rata-rata sebesar 87,5 dan standar deviasinya sebesar 17,5. Berdasarkan skor-skor tersebut, selanjutnya dibuatlah kategorisasi. Subjek digolongkan ke dalam tiga ketegori rasa empati, yaitu tinggi, sedang, dan rendah. Secara ringkas perhitungan kategorisasi dapat dilihat pada Tabel 2. 
Tabel 2

Tabel Distribusi Frekuensi Data Rasa Empati

\begin{tabular}{cccc}
\hline Kategori & Rentang Skor & Frekuensi & $\begin{array}{c}\text { Persentase } \\
(\mathbf{\%})\end{array}$ \\
\hline Rendah & $35-69$ & 6 & $6,25 \%$ \\
\hline Sedang & $70-104$ & 84 & $87,50 \%$ \\
\hline Tinggi & $105-140$ & 6 & $6,25 \%$ \\
\hline & Total & 96 & $100 \%$ \\
\hline
\end{tabular}

Berdasarkan Tabel diatas dapat dilihat bahwa subjek yang memiliki rasa empati rendah sebanyak 6 orang $(6,25 \%)$, subjek yang memiliki rasa empati sedang sebanyak 84 orang $(87,5 \%)$, dan subjek yang memiliki rasa empati tinggi sebanyak 6 orang $(6,25 \%)$.

Berdasarkan skor yang diperoleh, didapatkan gambaran umum skor interaksi sosial yang dihitung berdasarkan skor ideal. Diperoleh gambaran tentang interaksi sosial dengan skor minimum sebesar 32, skor maximum sebesar 128, rata-rata sebesar 80, dan standar deviasinya sebesar 16. Selanjutnya skor-skor di kategorisasi. Subjek digolongkan ke dalam tiga kategori interaksi sosial, yaitu tinggi, sedang, dan rendah.. secara ringkas perhitungan kategorisasi dapat dilihat pada Tabel 3 .

Tabel 3

Tabel Distribusi Frekuensi Data Interaksi Sosial

\begin{tabular}{cccc}
\hline Kategori & $\begin{array}{c}\text { Rentang } \\
\text { Skor }\end{array}$ & Frekuensi & $\begin{array}{c}\text { Persentase } \\
(\mathbf{\%})\end{array}$ \\
\hline Rendah & $32-63$ & 0 & $0 \%$ \\
\hline Sedang & $64-95$ & 56 & $61,45 \%$ \\
\hline Tinggi & $96-128$ & 40 & $41,66 \%$ \\
\hline & Total & 96 & $100 \%$ \\
\hline
\end{tabular}

Berdasarkan Tabel diatas dapat dilihat bahwa subjek yang memiliki interaksi sosial rendah sebanyak 0 orang $(0 \%)$, subjek yang memiliki interaksi sosial sedang sebanyak 59 orang $(61,45 \%)$, dan subjek yang memiliki interaksi sosial tinggi sebanyak 40 orang $(41,66 \%)$.

Uji hipotesis dilakukan untuk mengetahui apakah ada korelasi ganda yang signifikan antara penyesuian diri dan rasa empati dengan interaksi sosial siswa.Uji hipotesis korelasi Product Moment Pearson dan korelasi ganda menggunakan softwere Statistical Packages for Social 
Science (SPSS) for Window Release 16.00 Product Moment. Hasil uji hipotesis dapat di lihat pada tabel 4.

Tabel 4

Tabel Korelasi

\begin{tabular}{|c|c|c|c|c|}
\hline & & $\begin{array}{c}\text { Penyesuaian } \\
\text { Diri }\end{array}$ & Rasa Empati & $\begin{array}{c}\text { Interaksi } \\
\text { Sosial }\end{array}$ \\
\hline \multirow{3}{*}{$\begin{array}{l}\text { Penyesuaian } \\
\text { Diri }\end{array}$} & $\begin{array}{l}\text { Pearson } \\
\text { Correlation }\end{array}$ & 1 & $.802^{* *}$ & $.521^{* *}$ \\
\hline & Sig. (2-tailed) & & .000 & .000 \\
\hline & $\mathrm{N}$ & 96 & 96 & 96 \\
\hline \multirow{3}{*}{ Rasa Empati } & $\begin{array}{l}\text { Pearson } \\
\text { Correlation }\end{array}$ & $.802^{* *}$ & 1 & $.483^{* *}$ \\
\hline & Sig. (2-tailed) & .000 & & .000 \\
\hline & $\mathrm{N}$ & 96 & 96 & 96 \\
\hline \multirow{3}{*}{ Interaksi Sosial } & $\begin{array}{l}\text { Pearson } \\
\text { Correlation }\end{array}$ & $.521^{* *}$ & $.483^{* *}$ & 1 \\
\hline & Sig. (2-tailed) & .000 & .000 & \\
\hline & $\mathrm{N}$ & 96 & 96 & 96 \\
\hline
\end{tabular}

Berdasarkan hasil perhitungan korelasi antara penyesuian diri dengan interaksi sosial menunjukkan koefesien korelasi $\left(\mathrm{r}_{\mathrm{x} 1 \mathrm{y}}\right)$ sebesar 0,512 dengan tingkat signifikansi $0.000 \mathrm{p}<0,05$ berarti Ho ditolak dan Ha diterima, Jika penyesuian diri tinggi maka interaksi sosial tinggi. Terdapat hubungan yang signifikan antara penyesuian diri dengan interaksi sosial. Berdasarkan hasil perhitungan korelasi antara rasa empati dengan interaksi sosial menunjukkan koefesien korelasi $\left(\mathrm{r}_{\mathrm{X} 2 \mathrm{Y}}\right)$ sebesar 0,802 dapat dilihat pada tabel 4.11 dengan tingkat signifikansi $0.000 \mathrm{p}<$ 0,05 berarti Ho ditolak dan Ha diterima. Rasa empati tinggi maka interaksi sosial siswa akan tinggi. Terdapat hubungan yang signifikan antara rasa empati dengan interaksi sosial.

Selanjutnya untuk mengetahui pengujian hipotesis korelasi antara penyesuaian diri (X1) rasa empati (X2) interaksi sosial (Y) perhitungan menggunakan softwere Statistical Packages for Social Science (SPSS) for Window Release 16.00 Product Moment pada tabel 5 sebagai berikut.

Tabel 5

Uji Korelasi Ganda

\begin{tabular}{cccc}
\hline Model & $\mathrm{R}$ & $\mathrm{R}^{2}$ & Sig F Change \\
\hline 1 & 0,532 & 0,684 & 0
\end{tabular}


Berdasarkan hasil analisis menunjukkan bahwa koefesien korelasi ganda $\left(\mathrm{R}_{\mathrm{x} 1 \mathrm{x} 2 \mathrm{y}}\right)$ sebesar 0.684 dengan tingkat signifikansi sebesar 0.000 yang berarti $\mathrm{p}<0,05$ jadi Ho ditolak dan Ha diterima. Disimpulkan bahwa ada korelasi yang signifikan antara penyesuaian diri dan rasa empati dengan interaksi sosial siswa. Koefisien determininasi $\left(R^{2}\right)$ 0,684 apabila diubah dalam bentuk persentase menjadi $68,4 \%$ artinya penyesuaian diri dan rasa empati mempengaruhi inteaksi sosial sebesar $68,4 \%$.

Ketika seseorang cenderung untuk melakukan penyesuaian diri tinggi dan rasa empati yang tinggi maka interaksi sosial sesorang juga dapat dikatakan tinggi. Remaja yang memiliki keterampilan sosial akan mampu mengungkapkan perasaan baik itu positif atau pun negatif, tanpa perlu melukai orang lain atau kehilangan pengakuan sosial. Penyesuaian diri merupakan perilaku yang perlu dipelajari, karena memungkinkan individu dapat berinteraksi, memperoleh respon positif atau negatif. Menurut Vita (dalam Tiyas, 2017: 15) empati sebagai respon individu terhadap emosi orang lain, seolah individu yang bersangkutan mengalami sendiri keadaan emosi serupa yang dialami oleh orang tersebut. Kemampuan empati dapat ditunjukkan dengan cara aktif terlibat bersama orang lain melalui ekspresi wajah dan gerakan tangan, konsentrasi yang memfokuskan pada kontak mata, memperhatikan gerak tubuh, ketertutupan fisik, dan melakukan sentuhan fisik.

Fenomena interaksi sosial telah lama menjadi bagian dari dinamika sekolah. interaksi sosial merupakan permasalahan yang umum terjadi di berbagai lingkungan, termasuk disekolah. Ketika seseorang tinggi untuk melakukan interaksi sosial maka kecenderungan untuk tinggi prestasi belajar.

Salah satu penyebab siswa melakukan interaksi sosial tersebut adalah untuk mencari popularitas. Kurangnya interksi sosial dan konsep diri membuat seseorang tinggi melakukan perilaku berreproduksi. Hal ini didukung hasil penelitian Wahyu (2013: 6) yang melaporkan bahwa tindakan interaksi sosial dan konsep diri berkorelasi dengan perilaku berreproduksi. Artinya semakin tinggi tindakan interaksi sosial dan konsep diri maka tinggi perilaku berreproduksi seseorang. Begitu juga sebaliknya, semakin rendah maka semakin rendah perilaku berreproduksi. Tingginya interaksi sosial tidak lepas dari perilaku konsep diri. 
Penyesuaian diri dan rasa empati yang harus dimiliki siswa menjadi tugas guru pembimbing untuk meningkatkannya. Hal itu guru pembimbing adalah guru yang mempunyai tugas, tanggung jawab, wewenang, dan hak secara penuh dalam kegiatan Bimbingan dan Konseling terhadap sejumlah peserta didik, termasuk dalam memberikan layanan BK kepada semua peserta didik di sekolah tempat dia bertugas dalam rangka mengantarkan peserta didik mencapai pertumbuhan dan perkembangan secara optimal.

\section{Kesimpulan}

Terdapat korelasi yang signifikan antara penyesuaian diri dengan interaksi sosial siswa. Semakin baik penyesuaian diri maka semakin baik interaksi sosial siswa. Terdapat korelasi yang signifikan antara rasa empati dengan interaksi sosial siswa. Semakin baik rasa empati maka semakin baik interaksi sosial siswa. Selain itu, terdapat korelasi yang signifikan antara penyesuaian diri dan rasa empati dengan interaksi sosial Semakin baik penyesuaian diri dan rasa empati maka baik interaksi sosial siswa.

\section{Daftar Pustaka}

Ardi, A L. (2016). Pola Interaksi Sosial Pelanggan Warkop Daeng Sija Beverly Hills Kota Makassar. Skripsi UIN Alauddin Makassar

Anwar, M K. (2016). Hubungan antara Konsep Diri dengan Interaksi Sosial Pada Perawat di Rumah Sakit Islam Surakarta. Jurnal Universitas Muhammadiyah Surakarta

Elviyatun, E. (2015). Upaya Peningkatan Sikap Empati Melalui Teknik Photovoice pada Siswa Kelas X Jurusan Kriya Kulit di SMK Negeri 1 Kalasan Tahun 2015/2016. Skripsi Universitas Negeri Yogyakarta

Fitriyah. (2016). Hubungan antara Empati dengan Kepribadian Altruistik. Skripsi Universitas Islam Negeri Sunan Ampel Surabaya

Latifah, S A. (2015). Hubungan Antara Kematangan Emosi Dan Penyesuaian Diri Pada Remaja Pondok Pesantren Al-Luqmaniyyah Yogyakarta, Skripsi Universitas Islam Negeri Sunan Kalijaga Yogyakarta

Retna, C. (2017). Hubungan Antara Konsep Diri Dengan Penyesuaian Diri Siswa Kelas X Man 3 Sleman Yogyakarta. Skripsi Universitas Islam Negeri Sunan Kalijaga Yogyakarta

Riduwan. (2010). Metode dan Teknik menyusun Proposal Penelitian. Bandung: Alfabeta

Rahayu, A R. (2016). Pola Interaksi Sosial Anak Asuh dalam Konteks Kesehatan Sosial (Studi Di Uptd Kampung Anak Negeri, Kota Surabaya). Skripsi Universitas Airlangga 
Rahma, A. (2016). Hubungan antara Penyesuaian Diri dengan Kemandirian Belajar Siswa Kelas X SMA Excellent Al - Yasini yang Tinggal di Pondok Pesantren. Skripsi Universitas Islam Negeri Maulana Malik Ibrahim

Tiyas, R T. (2017). Pengaruh Empati Terhadap Kepedulian Sosial Pada Remaja. Skripsi Universitas Muhammadiyah Malang

Wahyu, M. (2013). Hubungan antara Interaksi Sosial dan Konsep Diri dengan Perilaku Reproduksi Sehat Pada Siswa Kelas XI di Madrasah Aliyah Negeri (Man) Purworejo. Skripsi Universitas Negeri Semarang 